\title{
Aim for success: peer-led team learning supports first-year transition to college-level mathematics
}

\section{Janet Liou-Mark}

New York City College of Technology, CUNY, USA

\author{
A.E. Dreyfuss \\ New York City College of Technology, CUNY, USA \\ Sandie Han \\ New York City College of Technology, CUNY, USA
}

Laura Yuen-Lau

New York City College of Technology, CUNY, USA

Karmen Yu

New York City College of Technology, CUNY, USA

\section{Abstract}

Students graduating from high schools in the United States are often underprepared, unaware of, and surprised by the rigours of mathematics courses offered at universities, and consequently they find themselves repeating the same mathematics course in their first year. The Academic Inventory Module (AIM) for Success in Mathematics project at a minority-serving higher education institution in the United States was a pilot intervention for first-year students. The goal of the project was to decrease the failure rates of their first credit-bearing mathematics course, Fundamentals of Mathematics. The programme required the participants to attend a nine-hour mathematics preparation workshop before the start of the semester and a weekly Peer-Led Team Learning (PLTL) workshop offered with the mathematics course during the fall semester. This study examined the effects of PLTL workshops on the students' mathematics performances and persistence, and on their self-efficacy, task values, and goal orientation towards mathematics. Results showed students participating in peer-led workshops had statistically significantly higher grades and lower failure and withdrawal rates than those who did not participate. There were also significant differences in the students' attitudes toward mathematics. 
Keywords: collaborative learning; first-year college students; intermediate algebra; mathematics attitude; Peer-Led Team Learning; transition to college.

\section{Introduction}

Helping first-year students make a successful transition in succeeding in college mathematics has been a challenge. Every year in the United States, thousands of students graduate from high school academically unprepared for post-secondary education, despite their eligibility to attend a college. Approximately $60 \%$ of incoming undergraduates discover they are in need of remediation or developmental work in mathematics after their enrolment (National Center for Public Policy and Higher Education and Southern Regional Education Board, 2010). Standardised tests have reported that under-represented minorities in the United States, defined as African-American or Black, American Indian or Alaskan Native, Hispanic or Latino, Native Hawaiian or other Pacific Islander, in Science, Technology, Engineering and Mathematics (STEM) disciplines, do not perform well in mathematics compared to other racial groups. The College Board (2012) reports that $5 \%$ of African-Americans and $10 \%$ of Hispanics scored 600 or higher on the mathematics section of the Scholastic Aptitude Tests (SATs, a standardised test widely used for college admission), compared to $30 \%$ of Whites and $53 \%$ of AsianAmericans. Moreover, Aud et al. (2010) reported only $22 \%$ of the American College Testing (ACT, an alternative national college admissions examination) test-takers met the college readiness benchmarks in all four subjects, including mathematics. Similarly to the SAT profiles, African-American test takers had the lowest readiness rates, as only $3 \%$ of those of African descent met the benchmarks in all four subjects. Kena et al. (2014) found that although the percentages of high school graduates who had completed required mathematics courses increased between 1990 and 2009, the percentage of Hispanic and African-American high school graduates completing Calculus remained low at $9 \%$ and $6 \%$ respectively in 2009. These low percentages call for post-secondary institutions to provide effective interventions to assist under-represented minorities in their transition to collegelevel mathematics.

The Academic Inventory Module (AIM) for Success in Mathematics project, at a higher education institution with significant numbers of under-represented minorities in the United States, addressed the need for an academic intervention by providing a first-year 
experience that supported student transition into credit-bearing mathematics coursework, as well as increased the student engagement and persistence in these courses. Based on the components of the Peer-Led Team Learning (PLTL) model (see www.pltlis.org), the AIM for Success in Mathematics project focused on activities that created a seamless pathway from developmental to credit-bearing Mathematics courses through a 'community of practice' concept (Lave and Wenger, 1991). Peer-led workshops were organised to support first-year students enrolled in Fundamentals of Mathematics, a course that covered selected topics in algebra and geometry.

\section{The Peer-Led Team Learning model}

Peer-Led Team Learning (PLTL) is an instructional model that supports student learning in a collaborative workshop setting led by an undergraduate peer leader (Gosser et al., 2001). A typical workshop session at this study's college involves eight to ten students in a team guided by a peer leader, who meet for one hour a week to complete problem sets consisting of challenging and carefully structured problems. These problems emphasise key course concepts, provide a means to guide students' efforts in effective collaboration, and demonstrate applications that are meaningful and relevant to the students. The weekly workshops provide an opportunity for students to discuss their understanding of the concepts presented in the lecture and the textbook in a collegial environment. Professors monitor the process and assist in designing problems relevant to the topics being taught in the lecture, however, they do not participate in the group activities.

The peer leaders are the crux of the PLTL model, differentiating it from other methods of collaborative learning (Quitadamo et al., 2009). Peer leaders are students who have previously done well in the course and they are formally trained for their role. They facilitate their workshop by ensuring that the team members are engaged with the exercises and with their peers, by encouraging trust and raising confidence, and by promoting enthusiastic debates and healthy discussions. Additionally, the peer leaders serve as role models, keeping students on task, providing direction and guidance, and using language that can easily be understood. 
A sustainable PLTL model includes strong institutional support that provides funding and recognition for the faculty and student peer leaders. These points are highlighted as the PLTL Six Critical Components which were developed through many years of evaluations of PLTL programmes:

1. Workshops are integral to the course.

2. A Faculty is involved with the workshops.

3. Peer leaders are trained and supervised.

4. Materials are appropriately challenging.

5. Suitable time and space are designated for workshop sessions.

6. There is institutional support.

When the six critical components are followed, the model has the possibility of becoming well-integrated in the institutional culture.

\section{The impact of peer-led workshops}

Studies have demonstrated an immense improvement in student performance where peerled workshops were a required component in Chemistry courses. Results have shown that students who participate in these workshop sections received A ('90-100'), B ('80-89'), or C ('70-79') grades ('marks') at higher rates than those students who have not had a peerled workshop (Hockings et al., 2008; Lyon and Lagowski, 2008; Gafney, 2001a). Moreover, students are less likely to withdraw from introductory Chemistry courses (Gafney, 2001a), and they are more likely to persist to higher-level science courses (Wamser, 2006).

In mathematics, there are only a few studies reported in implementing peer-led workshops. In an earlier study of students in a Precalculus course, Liou-Mark et al. (2010) found that the pass rates ( $A B C$ grades) for workshop participants were $30 \%$ higher than the non-participants with the same instructor and the withdrawal rates were $7.5 \%$ lower among workshop participants than for non-participants. Furthermore, the participants reported that the engagement with peer leaders and with other workshop participants created an inviting and encouraging environment to work on mathematics problem sets. 
The term, Peer-Assisted Learning (PAL) is often used synonymously with the Supplemental Instruction (SI) model: a group study method led by a trained student facilitator that is not integrated within the course (Arendale, 1993). A study by Cheng and Walters (2009) at the University of Minnesota using the SI model found that facilitator-led workshops improved students' grades in two mathematics courses, Algebra and Probability and Precalculus. Students who attended a weekly 50-minute optional workshop were ten times more likely to achieve a grade of $\mathrm{C}$ - or higher, rather than a $\mathrm{D}+$ or below (including failures and withdrawals).

Other studies have also shown evidence that peer-assisted workshops help improve Calculus success. In a study conducted at California State University in Los Angeles, Subramanian et al. (2009) found students who worked collaboratively on the homework assignments in supplemental workshops twice a week showed significant improvement in Calculus compared with those who did not participate in the workshop. A study conducted by Parkinson (2009) at Dublin City University, the School of Biotechnology in Ireland, found that peer-assisted learning in Calculus led by second-year students significantly changed first-year student performance results. In this study, the group that received peer tutoring showed higher exam grades and lower failure rates than the control group that had not received peer tutoring. Similarly, a Peer-Assisted Study Session (PASS) programme at Ulster University in Northern Ireland (Condell et al., 2011) found that students who participated in the Mathematics II module (topics include programming, statistics, and mathematical modelling) had improved average grades. Likewise, Duah et al. (2014) implemented the PAL scheme in a first-year mathematics course, Vector Spaces, at the School of Mathematics at Loughborough in the United Kingdom, and results showed that the final examination scores for PAL participants were higher than the non-participants, even after controlling for lecture attendance and prior attainment. Moreover, the PAL model was found to be effective in reducing the 'cooling off' phenomenon, i.e. students losing the motivation to pursue a degree in mathematics.

Malm et al. (2011) examined the impact of peer-assisted SI workshops on student success in five engineering programmes at the School of Engineering at Lund University in Sweden. The challenging courses required in the engineering school were identified as Single Variable Calculus I and II and Linear Algebra. Students in these courses were encouraged to attend SI workshops led by senior students. For all three courses, the pass rates for students who attended the workshops were significantly higher than those who 
did not attend the workshops. For the Calculus I and II sequence, the pass rate for students who frequently attended the workshops was $79 \%$, compared to a pass rate of $39 \%$ of those students who did not attend. In addition, students who attended the workshops reported higher course grades than those who did not attend. Furthermore, Malm et al. (2010) reported that the SI workshops had an immense impact on the educational progress of the students; $79 \%$ of the workshop participants met the credit requirement for the first-year engineering programme, whereas only $55 \%$ of non-workshop participants met the credit requirement. In a survey distributed to all students in the five engineering programmes, $67 \%$ of students agreed that the workshops had developed their problem-solving skills, and 68\% felt that the workshops had given them a deeper understanding of the subject. Moreover, 57\% agreed that the workshops had developed their ability to work collaboratively in a group setting, and $91 \%$ agreed that it was easy to ask questions during the workshop.

Horwitz and Rodger (2009) found that introducing a PLTL programme in introductory computer science courses at eight universities in the United States was successful in attracting under-represented minority students and women. Through participation in the PLTL programme, the retention and pass rates were significantly improved, especially for women.

\section{Methodology}

In an urban minority-serving technical college, Fundamentals of Mathematics is the first credit-bearing course that students take after remediation ('no credit-bearing courses'). The term 'minority-serving institutions' in the United States provides tertiary education where the student populations reach threshold categorisations of $35 \%$ AfricanAmerican/Black, American Indian or Alaskan Native, Hispanic or Latino, Native Hawaiian or other Pacific Islander. The Fundamentals of Mathematics course covers topics in intermediate algebra and geometry, and it is required of all Science, Technology, Engineering and Mathematics (STEM) majors. Each year, at least $10 \%$ of the total student population at this institution is enrolled in the course. The pass rate for this course is generally between 57 to $65 \%$, with fewer than $50 \%$ of the students receiving a grade of $\mathrm{C}$ or higher, according to institutional data. 


\section{Participants}

The participants in this study were first-year undergraduates enrolled in the Fundamentals of Mathematics course during the Fall 2009 semester. There were three distinct cohorts defined as follows.

1) Cohort I was comprised of 22 students who voluntarily participated in the AIM for Success project and fulfilled the following criteria: 1) attended a nine-hour summer mathematics preparation workshop; 2) enrolled in Fundamental of Mathematics during the Fall 2009 semester; and 3) participated in at least six one-hour peer-led workshops during the Fall 2009 semester out of a total of ten sessions.

2) Cohort II was comprised of 23 students enrolled in a Fundamentals of Mathematics class with a one-hour PLTL workshop component embedded in the course. Out of 33 students enrolled in this class, only the 23 first-year students taking the course for the first time were selected to be included in Cohort II for this study. Similarly to Cohort I, Cohort II also had a self-selection bias because students had knowingly registered for the course because of its additional one-hour workshop support and the participants were also given a free mathematics textbook. Cohort II students, however, had not participated in the summer mathematics preparatory workshop, but also attended at least six of the ten workshop sessions.

3) Cohort III was a comparison group that consisted of 20 first-year undergraduate students. These students were enrolled in a learning community; a restructured curriculum that linked courses so that greater coherence between courses is fostered and interpersonal connections among students and faculty are strengthened (Tinto, 2003). This Fundamentals of Mathematics course was connected to a first-year English composition class, and the learning community was designed to keep the same group of students together for these two classes. The learning community mathematics class was chosen as the comparison group because the group shares the same conceptual goal as the AIM for Success in Mathematics project; that is, to provide support for first-year students through a community of learning and practice.

Lastly, the institutional data on all students who registered for Fundamentals of Mathematics during the Fall 2009 semester provided a baseline comparison. The data from the three cohorts were measured against the average Fundamentals of Mathematics performance of all those sections at the college during the Fall 2009 semester. 
Combining Cohorts I and II, 73.3\% (33) from a total of 45 participants were from underrepresented minority groups, $53.3 \%$ (24) were females, and $46.7 \%$ (21) were males. Cohort III comprised $75 \%$ (15) students from under-represented minority groups, with a gender breakdown of $45 \%$ (9) females and $55 \%$ (11) males. Informed consent was obtained from the participants in Cohorts I and II.

\section{Project design}

The AIM for Success in Mathematics project provided two PLTL intervention strategies for first-year participants enrolled in a Fundamentals of Mathematics course. The participants in the PLTL intervention (Cohort I and II) were voluntary, and non-participation did not affect their grades.

The first PLTL intervention involving Cohort I was structured to include a nine-hour summer mathematics preparatory workshop followed by 'freestanding' PLTL workshops during the Fall 2009 semester. The nine-hour mathematics preparatory workshop, spread over three days, was offered one week before the start of the Fall 2009 semester. During this session, Cohort I participants worked with a mathematics professor and two peer leaders in reviewing key algebraic concepts covered in Fundamentals of Mathematics. Those who completed the nine-hour workshop were rewarded with a free mathematics textbook.

During the fall semester, Cohort I participants were required to attend a 'freestanding' PLTL workshop. The term 'freestanding' means the workshop was not tied to a particular Fundamentals of Mathematics section or instructor. There were five freestanding workshops scheduled on different days and times during the week so that students could choose the session that fit their personal and class schedules.

The second PLTL intervention structure involving Cohort II was the 'embedded' workshop, where students participated in PLTL workshops that were integrated into the course structure. The workshops were scheduled immediately after a class lecture once a week, and students met for one hour to work on sets of problems (known as 'modules'). Students were strongly encouraged by the instructor to participate in the embedded workshops, and students were informed that PLTL workshop participation or non-participation would not affect their grades. 
Both the freestanding and embedded PLTL workshops were facilitated by peer leaders, students who had done well in the course and were trained for their role. Each peer leader had previously worked through the full set of problems, so was familiar with the materials; each led the same group of students throughout the semester. The selection and training of the peer leaders is a critical component to the success of PLTL workshops. Peer leaders were required to have mastered precalculus or any higher-level mathematics courses. They were selected for their academic ability, usually a grade point average of 3.0 or higher (on a scale of 0 to 4 , or marks above 80 ), and they were chosen for their interpersonal and communication skills. Formal training was provided through a one-credit independent study course with a practicum component taught by a learning specialist. In this course, students learned several pedagogical techniques in promoting strong group dynamics which were experimented with and adopted in their workshops. They were also introduced to various learning theories in order to understand the processes of how people learn.

At the end of the project period (Fall 2009 semester, 15 weeks), the final course grades for Fundamentals of Mathematics were recorded for all the participants in Cohorts I, II, and III. The results were compared with the institutional data for all Fundamentals of Mathematics sections.

\section{Mathematics attitude and student experiences surveys}

This study also examined if there were differences in mathematics attitude before and after the PLTL intervention. Pre- and post-surveys on questions related to mathematics self-efficacy (Bong, 2002), task value (Bong, 2004), and goal orientation (Vandewalle, 1997) were given to the participants in Cohorts I and II. They completed the pre-survey on the first day of workshop and the post-survey one week before the end of the semester.

The statements on the survey found in Table 1 are based on a seven-point scale with 1 indicating 'strongly disagree' and 7 indicating 'strongly agree,' and they are divided into three categories. The first category, statements SE 1 - 5, addresses the students' sense of self-efficacy with regards to mathematics (Bong, 2002). Self-efficacy is one's belief or perception about one's capability to perform at a certain level on a task. A higher response in self-efficacy indicates that the student has strong motivation and a positive learning attitude (Bandura, 1994). The second section, statements TV $1-3$, addresses the 
students' sense of task values to mathematics (Bong, 2004). Task value refers to one's perception or the awareness about the task in terms of usefulness, importance, or applicability (Liu and Lin, 2010). A higher response in task values signifies a higher sense of mathematics relevance for the students. The last section, statements GO $1-12$, addresses the students' goal orientation (Vandewalle, 1997). Goal orientation concerns the underlying attitudes or motivation that give rise to action (Ryan and Deci, 2000). A higher response in goal orientation means the student is strongly motivated in mathematics by a particular type of goal orientation, whether it is intrinsic (motivation from the inner self) or extrinsic (motivation from outside factors such as grades, money, praise, or even fear of punishment).

At the end of the semester, participants in Cohorts I and II also completed a Student Experiences survey (Gafney, 2001b) evaluating the various aspects of the PLTL workshop involvement. The survey was based on a five-point scale with 1 indicating 'strongly disagree' and 5 indicating 'strongly agree.' Statements from the survey are listed in Table 2.

\section{Research questions}

The AIM for Success in Mathematics project focused on the following four research questions:

1) Did Fundamental of Mathematics students perform better with either PLTL workshop support than without it?

2) Which PLTL structure (embedded or freestanding) was associated with better performance outcomes?

3) What were the effects of PLTL workshops on the participants' self-efficacy, task value, and goal orientation with respect to mathematics?

4) What were participants' perceptions of the PLTL workshops? 


\section{Results}

The results from the study are reported by the respective research questions.

\section{1) Did Fundamental of Mathematics students perform better with either PLTL workshop support than without it?}

The overall results from this study showed that the impact of PLTL workshops on the Fundamental of Mathematics course grades was positive. The final grades for Cohort I (mathematics preparatory workshop and freestanding PLTL workshop participants) and Cohort II (embedded PLTL workshop participants) were higher and the failure rates were lower when compared with Cohort III (the comparison group) and the overall institution. The results are summarised in Figure 1.

Figure 1. Fundamentals of Mathematics grade distribution for Cohorts I, II, III, and the Institution in Fall 2009.

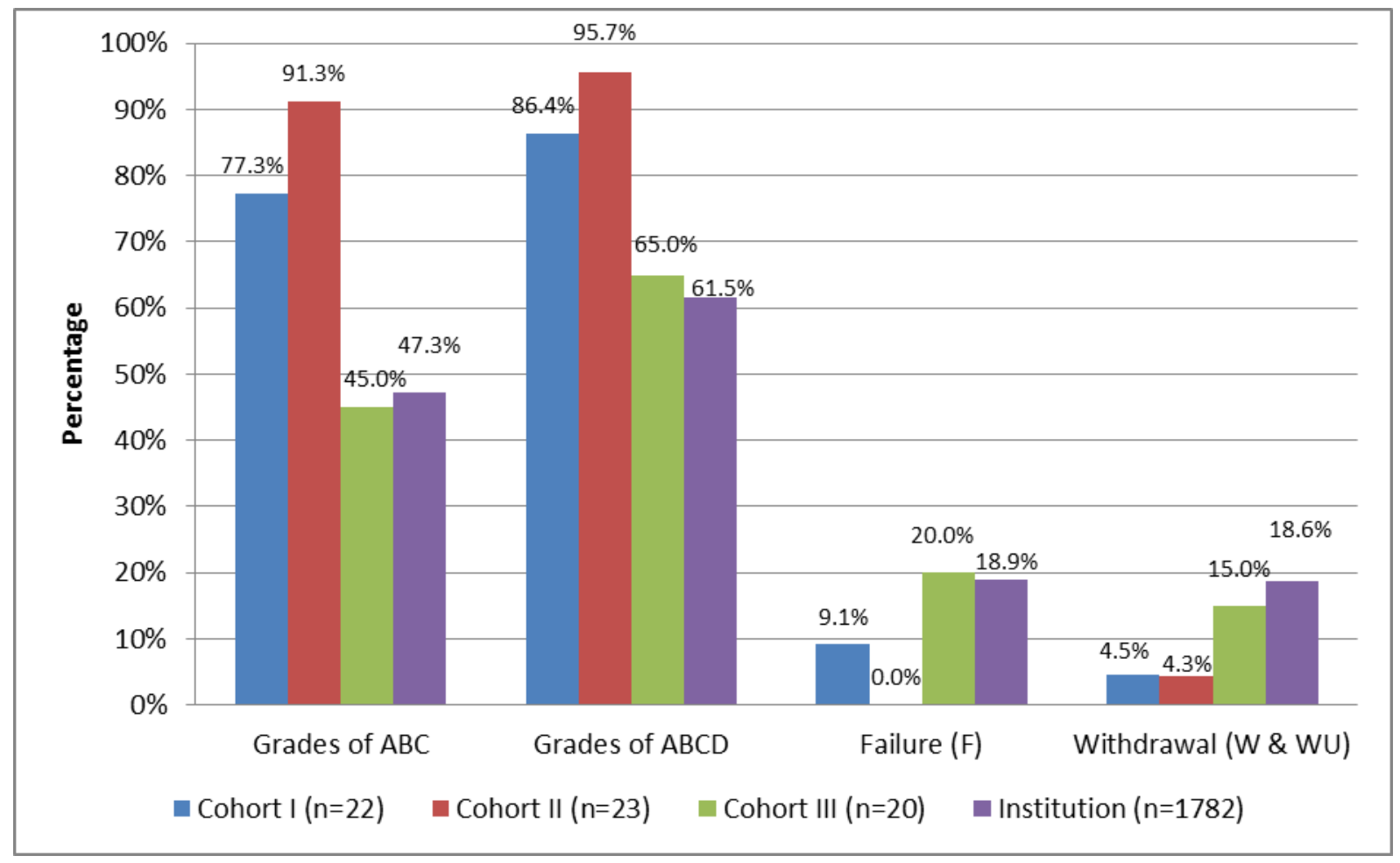

Across all the sections of the Fundamentals of Mathematics course, the institutional data reported that in Fall 2009, 47.3\% of the students received ABC grades, $37.5 \%$ withdrew or failed; and $14.2 \%$ received a 'D' grade (60-69), denoting little mastery of the subject. For Cohort I, $77.0 \%$ of the students received $A B C$ grades and $13.6 \%$ withdrew or failed. For Cohort II, $91.0 \%$ of these students received ABC grades, no one failed, and this group had 
the fewest withdrawals. For Cohort III, students performed about the same as the institutional average.

The results of this study show that first-year students enrolled in Fundamentals of Mathematics performed better with PLTL workshop support, either freestanding or embedded, than without it. Similarly, a meta-study by Arendale (2004) showed that highly structured study groups that are integrated into the course with trained facilitators have demonstrated better results compared to less structured programmes such as out-of-class tutoring. The PLTL workshop is highly structured such that each week the participants have a well-defined task (the problem sets) to complete. The problem sets follow the course outline and provide reinforcement to the concepts learned in class. Furthermore, the peer leaders are knowledgeable in the mathematics and they are trained to encourage students to stay on task.

\section{2) Which PLTL structure (embedded or freestanding) produced better performance outcomes?}

An independent sample's t-test was used to see if Cohort I, which had the extra mathematics preparatory workshop over the summer, performed better than Cohort II. Comparing the average final grade for Cohort I $(M=2.38, S D=1.3)$ and Cohort II $(M=2.77$, $S D=1.0)$, the t-test showed no statistically significant difference $[t(43)=1.125, p=.267]$ in the average final grade.

A Pearson correlation coefficient was used to determine whether or not the number of workshops attended during the Fall 2009 semester affected students' grades. Results showed a moderate positive correlation $(r=0.52)$ between the number of workshops attended and Fundamentals of Mathematics course grades.

Both the embedded workshops and the freestanding workshops used the same problem sets and were facilitated by peer leaders. However, the results indicate that there was no significant difference between students who participated in the embedded workshops and those who participated in the freestanding workshops with the additional nine-hour preparation. The major contributing factor to the differences in performance appears to be workshop attendance. The attendance in the embedded workshop by the Cohort II participants was better than the attendance of the freestanding workshop by the Cohort I 
participants. Clearly, if students did not attend the workshop, they would not benefit from the workshop. An explanation as to why the embedded workshop had better attendance may be that since it was tied directly to a particular class and instructor, it was better integrated into the course with well-structured weekly routines and tasks; it also formed a more closely-knit community of learning among the participants, peer leaders, and the instructor. The more flexible freestanding workshop, on the other hand, depended on the participants' motivation to attend; the instructor was neither directly nor indirectly involved in the workshop.

\section{3) What were the effects of PLTL workshops on the participants' self-efficacy, task value, and goal orientation with respect to mathematics?}

To evaluate the effects of PLTL workshops on the participants' self-efficacy, task value, and goal orientation with respect to mathematics, pre- and post-surveys were analysed. There were statistically significant differences (at the .10 alpha level) in the before and after attitudes regarding the following four statements: 1) I am certain I can understand the ideas taught in the mathematics course; 2) I expect to do very well in the mathematics class; 3) I am sure I can do an excellent job on the problems and tasks assigned in the mathematics class; and 4) I enjoy it when others are aware of how well I am doing. In summary, results showed having a positive mathematics self-efficacy provided students with the confidence to persist and overcome challenges in mathematics. Table 1 summarises the results of this survey. 


\section{Mathematics Self-efficacy (Bong, 2002)}

Modified version of Motivated Strategies for Learning Questionnaire (MSLQ)

( $1=$ strongly disagree and $7=$ strongly agree)

SE1. I am certain I can understand the ideas taught in the Mathematics course. **

SE2. I expect to do very well in the Mathematics class. *

SE3. I am sure I can do an excellent job on the problems and tasks assigned in the Mathematics class. *

SE4. I think I will receive a good grade in the Mathematics course.

\begin{tabular}{lll}
$\begin{array}{l}\text { Pre-survey } \\
\text { Mean (SD) }\end{array}$ & $\begin{array}{l}\text { Post-survey } \\
\text { Mean (SD) }\end{array}$ & $\begin{array}{l}\text { Paired Sample } \\
\text { T-test }\end{array}$ \\
\hline $4.98(1.49)$ & $5.75(1.50)$ & $t(43)=2.764, p=.008$ \\
$5.45(1.39)$ & $5.91(1.33)$ & $t(43)=1.829, p=.074$ \\
$5.00(1.48)$ & $5.52(1.34)$ & $t(43)=1.902, p=.064$ \\
$5.43(1.35)$ & $5.68(1.33)$ & $t(43)=0.968, p=.339$ \\
$5.45(1.41)$ & $5.86(1.25)$ & $t(43)=1.620, p=.113$
\end{tabular}

Task Values (Bong, 2002)

( $1=$ strongly disagree and $7=$ strongly agree)

TV1. I think what I learn about Mathematics is important.

$5.07(2.70)$

5.59 (1.85)

$t(43)=0.763, p=.450$

TV2. I think Mathematics is a useful subject.

$5.66(1.78)$

$5.73(1.62)$

$t(43)=0.228, p=.821$

$5.00(1.98)$

$5.00(2.00)$

$t(43)=0.000, p=1.000$

Goal Orientation (Vandewalle,1997)

( $1=$ strongly disagree and $7=$ strongly agree)

G01. I am willing to select a challenging assignment that I can learn a lot from.

GO2. I often look for opportunities to develop new skills and knowledge.

$\begin{array}{ll}5.10(1.48) & 5.41(1.50) \\ 5.31(1.54) & 5.50(1.61) \\ 5.17(1.25) & 5.23(1.75) \\ 5.12(1.21) & 5.32(1.67) \\ 4.64(1.43) & 4.59(1.90) \\ 4.71(1.61) & 4.36(1.98) \\ 4.88(1.73) & 4.36(2.07) \\ 4.58(1.53) & 4.50(2.05) \\ 4.29(1.53) & 3.82(1.83)\end{array}$

$t(41)=1.115, p=.271$

GO3. I enjoy challenging and difficult tasks where l'Il learn new skills.

GO4. I prefer to work in situations that require a high level of ability and talent.

GO5. I am concerned with showing that I can perform better than my colleagues.

GO6. I try to figure out what it takes to prove my ability to others.

GO7. I enjoy it when others are aware of how well I am doing.*

GO8. I prefer to work on projects where I can prove my ability to others.

G09. I would not avoid taking on a new task if there was a chance that I would appear rather

4.29 (1.53)

$3.82(1.83)$

$t(41)=0.503, p=.618$

$t(41)=0.077, p=.939$

$t(41)=0.682, p=.499$

$t(41)=0.368, p=.715$

incompetent to others.

G010. Avoiding a show of low ability is more important to me than learning a new skill.

$3.63(1.68) \quad 3.33(1.78)$

GO11. I'm concerned about taking on a task if my performance would reveal that I had low ability.

$4.02(1.69)$

$3.41(1.88)$

G012. I prefer to avoid situations where I might perform poorly.

$4.05(1.71) \quad 3.86(2.12)$

$t(41)=1.456, p=.153$

$t(41)=1.853, p=.071$

$t(37)=0.095, p=.925$

$t(41)=1.346, p=.186$

$$
{ }^{*} \mathrm{p}<.10 \quad{ }^{* *} \mathrm{p}<.01
$$

Table 1. Means, Standard Deviations, and Paired Sample T-Test results for Self-efficacy, Task Value, and Goal Orientation. 


\section{4) What were participants' perceptions of the PLTL workshops?}

Participants from Cohorts I and II responded favourably when surveyed on their experience with peer-led workshops. Statements were drawn from Gafney's (2001b) questionnaire as listed in Table 2. The students in Cohorts I and II felt strongly that the problem sets reflected the material taught in lecture. They perceived workshops as helping them prepare and perform better on exams. They strongly agreed that interacting with the peer leader and with the other group members increased their understanding of the material, and they felt comfortable asking questions. A student noted that 'It [peer-led workshops] helped me better understand the concepts through the extra help from peers and the workshop leaders'.

\section{Table 2. Means and Standard Deviations for responses on students' experiences with the Fundamentals of Mathematics PLTL Workshops (embedded and freestanding).}

\begin{tabular}{lr}
\hline Statements ( $\mathrm{n}=43)$ & $\begin{array}{c}\text { Mean (SD) } \\
\text { (strongly disagree) }-5 \text { (strongly agree) }\end{array}$ \\
\hline 1. The workshops are closely related to the material taught in the lectures. & $4.46(.59)$ \\
2. Workshops help me do better on tests. & $4.47(.67)$ \\
3. Interacting with the workshop leader increases my understanding. & $4.33(.75)$ \\
4. The workshop materials are helpful in preparing for exams. & $4.33(.65)$ \\
5. I believe that the workshops are improving my grade. & $4.44(.59)$ \\
6. Interacting with the other group members increases my understanding. & $4.26(.76)$ \\
7. I would recommend workshop courses to other students. & $4.49(.63)$ \\
8. In the workshops I am comfortable asking questions when I do not understand something. & $4.51(.60)$ \\
9. In the workshops I enjoyed interacting with the other students. & $4.67(.48)$ \\
10. The workshop experience led me to join formal or informal study groups related to & $3.67(.99)$ \\
\hline
\end{tabular}

\section{Discussion}

In a first credit-bearing mathematics course where enrolment is high and completion rate is low, the course is taken by mostly first-year students. The results of an additional hour of focused study in a group led by a peer leader were shown to be successful in increasing the first year students' engagement and performance in mathematics. While better performance by students who have participated in peer-led workshops has been a consistent finding in various studies, this study suggests that another factor is at play that 
has not previously been mentioned. That is, the workshop provided an open and safe learning environment where the participants built trust among the team members and with the peer leaders, and they met weekly to assist each other in the learning process.

Being comfortable in asking questions and in increasing one's understanding in mathematics suggest the first steps in entering the world of mathematics as a legitimate peripheral participant' (Lave and Wenger, 1991). Under the guidance of a novice-expert, (the peer leader), as well as the instruction of the expert (the instructor), students are beginning to be involved in a 'community of practice'. The relationships denoted by the participle 'interacting' speak to the nature of an academic apprenticeship, a relationship that is missing in the common view of the instructor-student dyad. Working within a group - a 'workshop' - of learners allows for the sharing of knowledge while working on challenging problems, seeing how others approach the material, and having a low threshold of fear that one 'looks incompetent' when asking a question.

In the PLTL programme, whether the workshop was embedded or freestanding, students were involved in an inherently less formal situation than the lecture alone. The discussion of problems and concepts then becomes situated in a collegial environment. The familiarity and comfortable interactions, coupled with the task at hand of learning mathematics, was a winning combination. Students may not have joined the community of mathematicians as yet, but they were legitimately involved in a nascent 'community of practice'.

\section{Recommendations for future studies}

Based on the results of the AIM for Success in Mathematics study, some suggestions in strengthening performance gains for first-year students may be aided by:

- Making workshops mandatory for the first credit-bearing course in mathematics: PLTL workshops should be made mandatory in a mathematics course since it is a challenge to motivate first-year students to attend an extra one-hour session.

- Providing incentives from the instructors to encourage students to participate in a PLTL workshop, e.g. a percentage of the grade devoted to workshop participation. 
- Encouraging instructor involvement in PLTL, e.g. designing and creating problem sets, maintaining constant communication with peer leaders.

Moreover, the AIM for Success in Mathematics project is a programme that could be replicated in higher education institutions, especially those which serve minority or lowincome populations. However, the following limitations should be considered:

- To truly test the effectiveness of the PLTL workshops, a random design study should be implemented, controlling for instructor and peer leader effects.

- An increase in participants in the study may help determine why a summer preparatory mathematics workshop was not effective.

- Although the study was only a semester long, a longitudinal study is recommended to include comparisons of how PLTL and non-PLTL participants perform in their next sequential mathematics course.

- An area of investigation suggested by observations and responses of the students in this study was how the emotional response the students have towards the peer leaders is related to the level of participation in the workshops.

- Since all the participants in the AIM for Success in Mathematics programme received a free textbook, this may be cost prohibitive, so other types of incentives should be considered.

\section{Conclusions}

With many students struggling in their first college mathematics course in the United States, it is imperative to implement strategies that will increase the persistence and success of these students. Because the majority of the study participants were from under-represented minority groups and were female, the results suggest that integrating first-year students with their peers, and having a peer as a leader facilitating the workshop group, will also help those from groups that have noticeably faltered in the transition from high school to college. More explicitly, PLTL workshops could provide a structure where students develop the language and skills to solve mathematical problems through their discussions, interactions, and relationships with each other and the peer leader. 
Since the pilot project in 2009, the institution has adopted the AIM for Success in Mathematics model for the Fundamentals of Mathematics course. Two sections with an embedded one-hour PLTL workshop are offered every semester, and its $A B C$ pass rates have been at least $15 \%$ higher when compared with the overall institutional data (LiouMark et al., 2014). Because of the positive pass rates, the PLTL workshop model has meanwhile expanded to the next four successive mathematics courses: Intermediate Algebra and Trigonometry, Precalculus, Calculus I and Calculus II.

Projects like the AIM for Success in Mathematics described in this study may also be a catalyst for attitudinal changes in mathematics. The residual effects from an increased level of confidence and motivation by the participants to persevere and perform in foundational mathematics may increase the number of students taking higher level mathematics courses. This positive direction would certainly assist the need for the United States to recruit more students in STEM disciplines.

\section{Acknowledgments}

This work was partially supported by the City University of New York Coordinated Undergraduate Education Grant, the Honors Scholars Program, and the Black Male Initiative. The authors wish to thank Dr. Pamela Brown, Dr. Reginald Blake, and Ms. Lauri Aguirre for their support, and Dr. Reneta Lansiquot for her partnership in this project. 


\section{References}

Arendale, D.R. (1993) 'Foundation and theoretical framework for Supplemental Instruction', in Martin, D.C. and Arendale, D.R. (eds.) Supplemental Instruction: improving first-year student success in high-risk courses (No.7). Columbia SC: National Resource Center for the Freshman Year Experience and Students in Transition, pp. 41-50.

Arendale, D.R. (2004) 'Pathways of persistence: a review of postsecondary peer cooperative learning programs', in Duranczyk, I.M., Higbee, J.L. and Lundell, D.B. (eds.) Best practices for access and retention in higher education. Minneapolis, MN: Center for Research on Developmental Education, General College, University of Minnesota, pp. 27-40.

Aud, S., Fox, M. and Kewal Ramani, A. (2010) Status and trends in the education of racial and ethnic groups (NCES 2010-015). U.S. Department of Education, National Center for Education Statistics. Washington, DC. Available at: http://nces.ed.gov/pubs2010/2010015.pdf (Assessed: 5 December 2013).

Bandura, A. (1994) 'Self-efficacy', in Ramachaudran, V.S. (ed.) Encyclopedia of human behaviour (Vol. 4). New York: Academic Press, pp. 71-81.

Bong, M. (2002) 'Predictive utility of subject-, task-, and problem-specific self-efficacy judgments for immediate and delayed academic performance', Journal of Experimental Education, 70(2), pp. 133-162.

Bong, M. (2004)'Academic motivation in self-efficacy, task value, achievement goal orientations, and attributional beliefs', Journal of Educational Research, 97(6), pp. 287-297.

Cheng, D. and Walters, M. (2009) 'Peer-assisted learning in mathematics: an observational study of student success', Journal of Peer Learning, 2(1), pp. 23-39. 
College Board (2012) Percentile ranks for 2012 college-bound seniors'. Available at: http://media.collegeboard.com/digitalServices/pdf/research/SAT-Percentile-Ranksby-Gender-Ethnicity-2012.pdf (Assessed: 5 December 2013).

Condell, J.V., Zacharopoulou, A., Giles, M. and O'Neill, L. (2011) 'Engaging and supporting students in mathematics through Peer Assisted Study Session Support at Ulster (PASS @ Ulster) - a comparison with psychology and law', International Conference on Engineering Education (ICEE) - Engineering Sustainability for a Global Economy. Belfast, UK 21-26 August.

Duah, F., Croft, T. and Inglis, M. (2014) 'Can peer assisted learning be effective in undergraduate mathematics?', International Journal of Mathematical Education in Science and Technology, 45(4), pp. 552-565.

Gafney, L. (2001a) 'Chapter 6: workshop evaluation', in Gosser, D.K., Cracolice, M.S., Kampmeier, J.A., Roth, V., Strozak, V. and Varma-Nelson, P. (eds.) Peer-led team learning: a guidebook. Upper Saddle River, NJ: Prentice Hall, pp. 75-93.

Gafney, L. (2001b) ‘Appendix III: student survey’, in Gosser, D.K., Cracolice, M.S., Kampmeier, J.A., Roth, V., Strozak, V. and Varma-Nelson, P. (eds.) Peer-led team learning: a guidebook. Upper Saddle River, NJ: Prentice Hall, pp. 129-133.

Gosser, D.K., Cracolice, M.S., Kampmeier, J.A., Roth, V., Strozak, V. and Varma-Nelson, P. (2001) Peer-led team learning: a guidebook. Upper Saddle River, NJ: Prentice Hall.

Hockings, S.C., DeAngelis, K.J. and Frey, R.F. (2008) 'Peer-led team learning in general chemistry: implementation and evaluation', Journal of Chemical Education, 85(7), pp. 990-996.

Horwitz, S. and Rodger, S. (2009) 'Using peer-led team learning to increase participation and success of under-represented groups in introductory computer science', The 40th ACM Technical Symposium on Computer Science Education: Proceedings of SIGCSE 2009. Chattanooga, TN, USA 4-7 March. New York: ACM, pp. 163-167. 
Kena, G., Aud, S., Johnson, F., Wang, X., Zhang, J., Rathbun, A., Wilkinson-Flicker, S. and Kristapovich, P. (2014) The condition of education 2014 (NCES 2014-083). U.S. Department of Education, National Center for Education Statistics. Washington, DC.

Lave, J. and Wenger, E. (1991) Situated learning: legitimate peripheral participation. Cambridge, UK: Cambridge University Press.

Liou-Mark, J., Dreyfuss, A.E. and Younge, L. (2010) 'The implementation of peer assisted learning workshops in precalculus: an approach to increasing student success', Mathematics and Computer Education, 44(3), pp. 249-259.

Liou-Mark, J., Han, S., Ahmed, M., Anglade, F. and Young, J. (2014) 'Strengthening foundational mathematics courses through the implementation of peer-led workshops', 2013 Conference Proceedings of the Peer-Led Team Learning International Society. University of Houston-Downtown, Texas 30 May - 1 June 2013. ISSN 2329-2113. Available at: http://pltlis.org/wpcontent/uploads/2015/10/Liou-Mark-Han-Ahmed-Anglade-Young-2013.pdf (Accessed: 10 November 2015).

Liu, E.Z.F. and Lin, C.H. (2010) 'The survey study of mathematics motivated strategies for learning questionnaire (MMSLQ) for grade 10 - 12 Taiwanese students', TOJET: The Turkish Online Journal of Education Technology, 9(2), pp. 221-233.

Lyon, D.C. and Lagowski, J.J. (2008) 'Effectiveness of facilitating small-group learning in large lecture classes', Journal of Chemical Education, 85(11), pp. 1571-1576.

Malm, J., Bryngfors, L.E. and Morner, L.L. (2010) 'Supplemental Instruction (SI) at the faculty of engineering (LTH), Lund University, Sweden. An evaluation of the SIprogram at five LTH engineering programs autumn 2008', Journal of Peer Learning, 3(1), pp. 38-50.

Malm, J., Bryngfors, L.E. and Morner, L.L. (2011) 'Improving student success in difficult engineering education courses through Supplemental Instruction (SI) - what is the impact of the degree of SI attendance?', Journal of Peer Learning, 4(1), pp.16-23. 
National Center for Public Policy and Higher Education \& Southern Regional Education Board (2010) Beyond the rhetoric: improving college readiness through coherent state policy. San Jose, CA: National Center for Public Policy and Higher Education; and Atlanta, GA: Southern Regional Education Board.

Parkinson, M. (2009) 'The effect of peer assisted learning support (PALS) on performance in mathematics and chemistry', Innovations in Education and Teaching International, 46(4), pp. 381-392.

Quitadamo, I.J., Brahler, C.J., and Crouch, G.J. (2009) ‘Peer-led team learning: a prospective method for increasing critical thinking in undergraduate science courses', Science Educator, 18(1), pp.29-39.

Ryan, R. and Deci, E. (2000) 'Intrinsic and extrinsic motivations: classic definitions and new directions', Contemporary Educational Psychology, 25(1), pp. 54-67.

Subramanian, P.K., Cates, M. and Gutarts, B. (2009) 'Improving calculus success rates at California State University Los Angeles', Journal of Mathematics and Computer Education, 43(3), pp.259-269.

Tinto, V. (2003) 'Learning better together: the impact of learning communities on student success in higher education', Higher Education Monograph Series 2003-1. Higher Education Program, School of Education, Syracuse University, 1-8. Available at: http://www.nhcuc.org/pdfs/Learning Better Together.pdf (Accessed: 15 September 2014).

Vandewalle, D. (1997) 'Development and validation: a work domain goal orientation instrument', Educational and Psychological Measurement, 57(6), pp. 995-1015.

Wamser, C.C. (2006) 'Peer-led Team Learning (PLTL) in organic chemistry: student performance, success, and persistence in the course', Journal of Chemical Education, 83(10), pp.1562-1566. 


\section{Author details}

Janet Liou-Mark is a Professor of Mathematics at New York City College of Technology of the City University of New York (CUNY), USA. As a result of her research interest in the implementation of Peer-Led Team Learning (PLTL) instructional model in mathematics she was awarded the 2011 CUNY Chancellor's Award for Excellence in Undergraduate Mathematics Instruction. She has received numerous national grants in which PLTL is a vital component to student success. She has published her research and presented her work with undergraduates at national and international conferences.

\section{A.E. Dreyfuss is a Learning Specialist/Developer who has worked with Peer-Led Team} Learning in disseminating this instructional model, currently through the Peer-Led Team Learning International Society, serving as its first President (www.pltlis.org). Her work in the field of Adult Learning and Leadership has included developing training for Peer Leaders, undergraduate students who facilitate learning for groups of students in various disciplines, as well as authoring publications on peer leading, the transition to college, and a guide for teaching for new faculties.

Sandie Han is the Chair and an Associate Professor of Mathematics at New York City College of Technology of the City University of New York (CUNY). She has extensive experience in programme design and administration, including administrative roles as the chair of the Mathematics Department, Computer Science Programme Coordinator, High School Programme Coordinator, as well as the Principal Investigator on the U.S. Department of Education Minority Science and Engineering Improvement Programme grant and Co-Principal Investigator on National Science Foundation Scholarship in STEM grants. She has several publications on the theory and practice of Self-Regulated Learning, mathematics self-efficacy, and Peer-Led Team Learning, and numerous local, national, and international presentations. Sandie's research on Self-Regulated Learning and self-efficacy has won her the 2013 CUNY Chancellor's Award for Excellence in Undergraduate Mathematics Instruction.

Laura Yuen-Lau is a Programme Coordinator of the Honours Scholars Programme and a project manager of the National Science Foundation Research Experience for Undergraduate (NSF REU) Programme at New York City College of Technology of the City University of New York (CUNY), USA. She supervises the Honours Scholars office 
and coordinates programme events such as cultural field trips, workshops, and seminars throughout the semester. Her passion and dedication for the programme and for the students has earned her two Outstanding Commitment Awards.

Karmen $\mathrm{Yu}$ is a doctoral student and research assistant for the Mathematics Education Ph.D. programme at Montclair State University, USA. Her research interest is in students' mathematical learning situated in the Peer-Led Team Learning (PLTL) instructional model. She helped to adapt the PLTL model at her institution and she has conducted a pilot study for the Noyce @ Montclair programme at Montclair State University. The results of the pilot study have been presented at local and national conferences. 